Aim of the study: This study explores the efficacy of oral glutamine in the prevention of acute radiotherapy-induced esophagitis in patients with lung cancer who are treated with thoracic radiotherapy.

Material and methods: This study was planned as a retrospective randomized experimental study. Forty-six patients with lung cancer, who were treated and kept under control between January 2008 and January 2010, were included in the study by the Department of Radiation Oncology, Faculty of Medicine, Dicle University. The patients were divided into two groups. The first group $(n=21)$ was given prophylactic oral powder glutamine (daily $30 \mathrm{~g}$ ), while the second group $(n=25)$ was not given oral glutamine.

Results: There were 21 patients in Group 1 (45.7\%) and 25 patients in Group 2 (54.3\%). No significant statistical difference was observed between the two groups in terms of age, gender, stage, histopathological type, treatment choice, received radiation doses, esophagus length in RT field, or location of the tumor $(p>0.05)$. A significant statistical difference was observed between the glutamine-supplemented group (first group) and the glutamine-free group (second group) according to the grade of esophagitis $(p<0.0001)$.

Conclusions: In our retrospective randomized experimental study, we determined that the severity of acute radiotherapy-induced esophagitis might be decreased with oral glutamine in patients with lung cancer who were treated with thoracic radiotherapy.

Key words: acute esophagitis, lung cancer, glutamine, thoracic radiotherapy, radioprotective.

Contemp Oncol (Pozn) 2013; 17 (6): 520-524 DOI: $10.5114 /$ wo.2013.38912

\section{The efficacy of oral glutamine in prevention of acute radiotherapy-induced esophagitis in patients with lung cancer}

Oznur Donmez Tutanc ${ }^{1}$, Akin Aydogan ${ }^{2}$, Seckin Akkucuk², Ahmet Taner Sunbul ${ }^{3}$, Seyit Burhanedtin Zincircioglu ${ }^{4}$, Gulistan Alpagat ${ }^{5}$, Ersin Sukru Erden ${ }^{6}$

${ }^{1}$ Department of Radiation Oncology, Antakya State Hospital, Antakya, Turkey ${ }^{2}$ Department of General Surgery, Medicine School of Mustafa Kemal University, Antakya, Turkey

3Department of Medical Oncology, Medicine School of Mustafa Kemal University, Antakya, Turkey

${ }^{4}$ Department of Radiation Oncology, Medicine School of Dicle University, Diyarbakır, Turkey ${ }^{5}$ Department of Internal Medicine, Medicine School of Dicle University, Diyarbakır,Turkey ${ }^{6}$ Department of Chest Diseases, Medicine School of Mustafa Kemal University, Antakya, Turkey

\section{Introduction}

Lung cancer is the second most prevalent cancer, following prostate cancer in men and breast cancer in women [1]. Chemotherapy (CT), radiotherapy (RT), surgery, or combined treatment protocols are used in treatment [2].

The aim of thoracic irradiation is to deliver an effective therapeutic dose to the tumor with an efficient dose to healthy tissues [3, 4]. The esophagus may be exposed to considerable amounts of radiation due to its location in the central thorax. Acute radiation-induced esophagitis is one of the side effects of thoracic RT [5-7].

Glutamine is an important radioprotective agent [4]. In hypercatabolic situations such as cancer, much of the glutamine will be provided by skeletal muscles. However, as time passes, glutamine depletion occurs because increased glutamine synthesis cannot keep up with the deficiency [8]. For this reason, giving glutamine to patients to prevent radiation-induced esophagitis is acceptable [6]. Several drugs are to be used to prevent radiation-induced esophagitis, and oral glutamine may be another choice [7, 9].

We aimed to ascertain the efficacy of oral glutamine in the prevention of acute radiation-induced esophagitis in patients with lung cancer who are treated with thoracic radiotherapy.

\section{Material and methods}

In this study, 316 files of patients with lung cancer who were treated and kept under control between January 2008 and January 2010 by the Department of Radiation Oncology, Faculty of Medicine, Dicle University were analyzed retrospectively. Forty-six patients who received thoracic irradiation, with no history of dysphasia, no known allergy to glutamine, and who received no dietary support besides glutamine were included in the study. All patients' Karnofsky performance statuses were $60 \%$ or more.

\section{Patient characteristics}

Thirty-nine patients were male and 7 patients were female. Non-small cell lung cancer (NSCLC) was present in 36 patients and small cell lung cancer (SCLC) was present in 10 patients cytopathologically. Only 20 of 36 patients with non-small cell lung cancer had further cytopathologic sub-types. Thir- 
teen of them were squamous cell carcinoma, and 7 tumors were adenocarcinoma. Two of 36 patients with NSCLC were diagnosed at stage IIA, 3 at stage IIIA, 29 at stage IIIB, and 2 at stage IV. Thirty-eight of 46 patients received both chemotherapy and radiotherapy, and 8 patients only received RT. Table 1 shows the properties of patients and tumors.

\section{Radiotherapy}

All patients' RT fields were planned via a simulator with a Nucletron Oldfelt band using the Simulix-HP model. By using thoracic computed tomography, tumor gross volume, clinically targeted volume, and therapy volume were determined. The first set up was determined and therapy fields were confirmed during the patient's first therapy session with a concerned doctor. All patients received RT 5 days a week. Different doses of RT according to the histopathologic grades of tumors were applied with a linear accelerator treatment device (General Electric, Saturn 43 F) using $10 \mathrm{mV}$ photon energy.

\section{Radiotherapy fields}

The radiotherapy area included primary tumors and metastatic lymph nodes with a $2 \mathrm{~cm}$ free border, all parts of the mediastinum, lymph nodes within $5 \mathrm{~cm}$ below the carina for tumors located in the upper lung and medial sided without subcarinal lymph node metastasis, the diaphragm (if the tumor was located in the bottom lobes), ipsilateral supraclavicular fossa (if the tumor was located in the upper lobes), and lymph nodes (Fig. 1). The medulla spinalis was excluded from the therapy field with a 46 Gy radiation dose.

The patients were classified according to the length of the esophagus in the therapy field (below or above $18 \mathrm{~cm}$ ) and according to RT doses (below or above $60 \mathrm{~Gy}$ ).

\section{Glutamine usage}

Patients were divided into two groups. Prophylactic oral glutamine was applied to 21 patients in Group 1. The daily dose was $30 \mathrm{~g}$ (10 g/8 hours with water), and the oral glutamine intake was started on the first day of thoracic irradiation, continued during therapy and post-therapy, and lasted for 3 weeks after RT. Twenty-five patients in Group 2 had not received oral glutamine or placebos. No additional medication was given to the patients in both groups for esophagitis.

\section{Analysis of patients and scoring for esophagitis}

Assessments of symptoms and toxicity of irradiation were made via routine physical examination and verbal interaction with all patients once a week during thoracic irradiation. Acute radiation-induced esophagitis was scored according to the acute esophagitis toxicity criteria of RTOG (Radiation Therapy Oncology Group) (Table 2).

\section{Data collection and statistical analysis}

The data were recorded and statistical analyses were performed using "SPSS 11.5 for Windows". Tables of pa-
Table 1. Patient and tumor characteristics

\begin{tabular}{|c|c|c|}
\hline Patient and tumor characteristics & $\begin{array}{c}\text { Number of } \\
\text { patients }\end{array}$ & $\%$ \\
\hline $\begin{array}{l}\text { Age } \\
60 \text { years and below } \\
\text { older than } 60 \text { years }\end{array}$ & $\begin{array}{l}23 \\
23\end{array}$ & $\begin{array}{l}50 \\
50\end{array}$ \\
\hline $\begin{array}{l}\text { Sex } \\
\text { male } \\
\text { female }\end{array}$ & $\begin{array}{c}39 \\
7\end{array}$ & $\begin{array}{l}84.8 \\
15.2\end{array}$ \\
\hline $\begin{array}{l}\text { Pathological diagnosis } \\
\text { NSCLC } \\
\text { stage IIA } \\
\text { stage IIIA } \\
\text { stage IIIB } \\
\text { stage IV } \\
\text { SCLC } \\
\text { limited stage }\end{array}$ & $\begin{array}{c}36 \\
2 \\
3 \\
29 \\
2 \\
10 \\
10\end{array}$ & $\begin{array}{c}78.3 \\
4.3 \\
6.5 \\
63.0 \\
4.3 \\
21.7 \\
21.7\end{array}$ \\
\hline $\begin{array}{l}\text { Treatment } \\
\text { simultaneous CRT } \\
\text { RT }\end{array}$ & $\begin{array}{c}38 \\
8\end{array}$ & $\begin{array}{l}82.6 \\
17.4\end{array}$ \\
\hline $\begin{array}{l}\text { RT dose } \\
60 \text { Gy and more } \\
\text { less than } 60 \text { Gy }\end{array}$ & $\begin{array}{l}31 \\
15\end{array}$ & $\begin{array}{l}67.4 \\
32.6\end{array}$ \\
\hline $\begin{array}{l}\text { Tumor localization } \\
\text { upper left lobe } \\
\text { lower left lobe } \\
\text { upper right lobe } \\
\text { lower right lobe }\end{array}$ & $\begin{array}{l}11 \\
13 \\
11 \\
11\end{array}$ & $\begin{array}{l}23.9 \\
28.3 \\
23.9 \\
23.9\end{array}$ \\
\hline
\end{tabular}

tient and tumor characteristics and treatment results were made and interpreted using the Spearman $\chi^{2}$ analysis. When the expected and observed values were less than 5 , the $p$ value was calculated according to Fisher's exact test. $P<0.05$ was accepted as statistical significance.

\section{Results}

Forty-six patients were included in the study and all data from them were statistically analyzed. Neither toxicity nor intolerance of glutamine was detected. No statistically significant difference was observed according to the patient and tumor characteristics $(p>0.05)$.

\section{Treatment results}

Grade I esophagitis occurred in 61.9\% $(n=13)$, grade II esophagitis in $33.3(n=7)$, and grade III esophagitis in $4.8 \%$ $(n=1)$ of patients in group 1 who had received glutamine. On the other hand, grade I esophagitis occurred in 8.0\% $(n=2)$, grade II esophagitis in $48.0 \%(n=12)$, and grade III esophagitis in $44.0 \%(n=11)$ of patients in group 2 who had not received glutamine. Grade II and grade III esophagitis were decreased in the treatment group. Statistically significant differences were observed between these two groups according to the grades of esophagitis $(p<0.0001)$ (Table 3)

All of the patients in both groups showed no statistically significant difference between grade of esophagitis and treatment modalities (chemoradiotherapy vs. radio- 


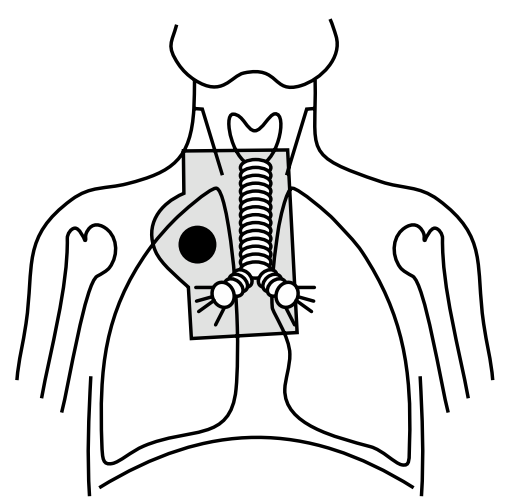

upper lobes
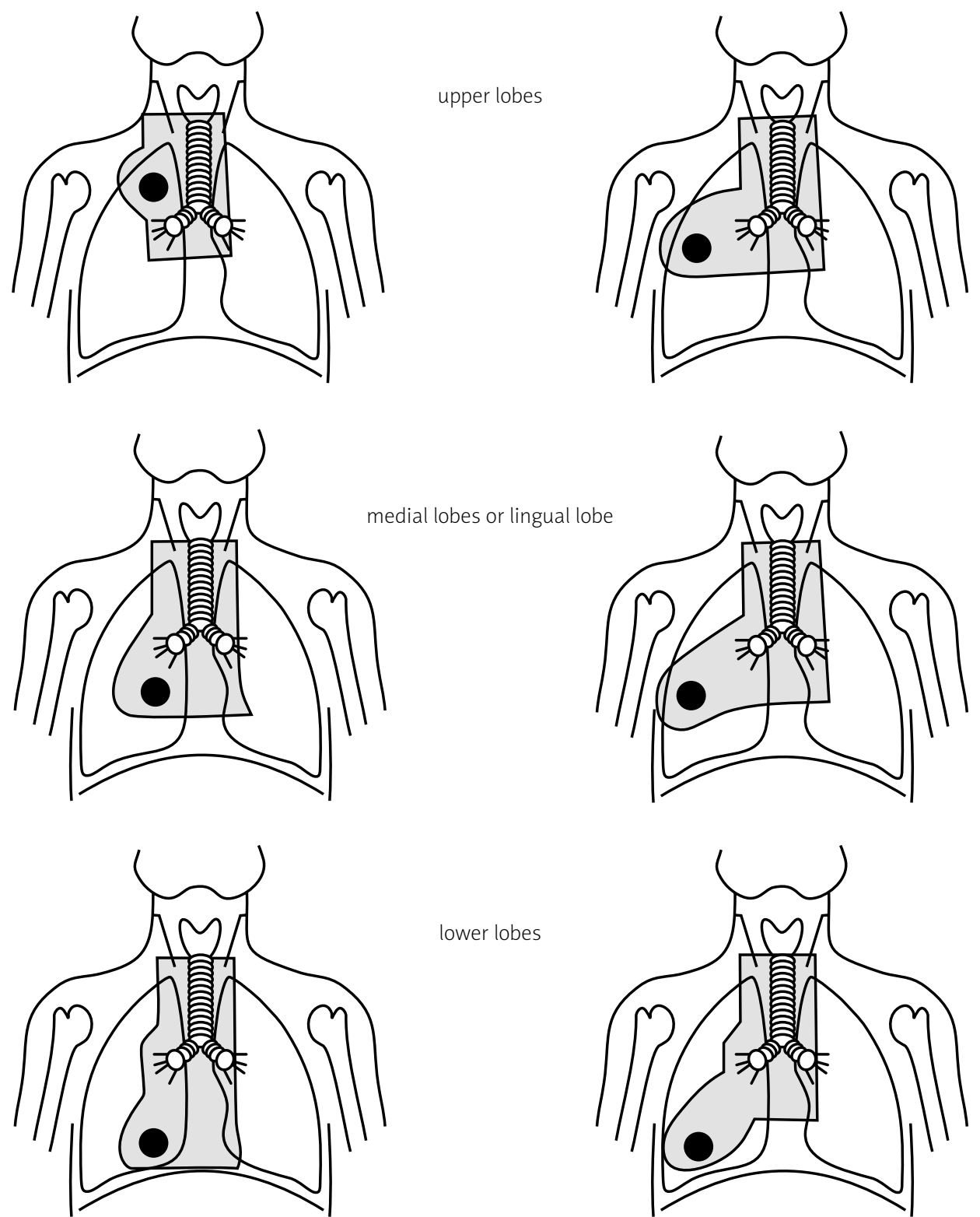

lower lobes

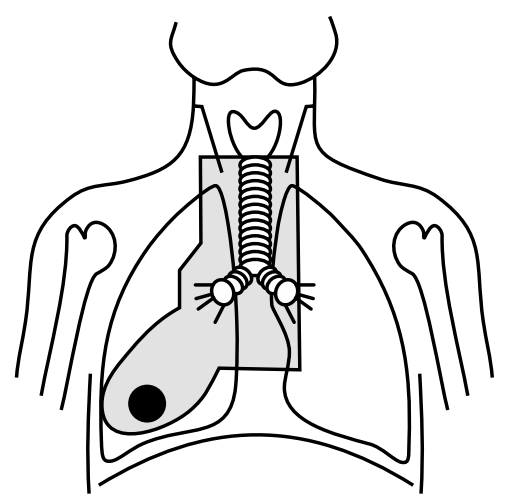

Fig. 1. Classical site drawings for conventional 2-dimension RT according to the primary tumor's localization in lung cancer. These areas were the target of the broad field of subclinical disease for RT [1]

therapy) ( $p=0.10$ ). Also, no statistically significant difference was observed when all the patients in the two groups were analyzed according to the relation between grades of esophagitis and histopathologic tumor types $(p=0.80)$.

Table 2. RTOG acute esophagitis scoring

\begin{tabular}{ll} 
Grade 0 & No difference \\
Grade I & $\begin{array}{l}\text { Mild dysphagia/odynophagia } \\
\text { Topical anesthetics, non-narcotic agents or diet } \\
\text { might be needed }\end{array}$ \\
Grade II & $\begin{array}{l}\text { Intermediate dysphagia/odynophagia } \\
\text { Narcotic drugs or pure liquid diet might be needed }\end{array}$ \\
Grade III & $\begin{array}{l}\text { Severe dysphagia/odynophagia } \\
\text { Dehydration or weight loss }>15 \% . \text { Nasogastric tube } \\
\text { might be required for nutrition }\end{array}$ \\
Grade IV & $\begin{array}{l}\text { Complete obstruction, ulceration, perforation/fistula } \\
\text { Grade V }\end{array}$ \\
\hline
\end{tabular}

No statistically significant difference was observed in the relationship between grades of esophagitis and irradiation doses $(p=0.70)$. Exposed length of the esophagus had no statistical relationship with grade of esophagitis $(p=0.83)$.

Table 3. Distribution of patients according to treatment results

\begin{tabular}{|c|c|c|c|}
\hline Esophagitis & $\begin{array}{c}\text { Group } 1 \\
\text { Glutamine } \\
(+)(\%)\end{array}$ & $\begin{array}{l}\text { Group } 2 \\
\text { Glutamine } \\
(-)(\%)\end{array}$ & $P$ \\
\hline Grade 1 & $13(61.9)$ & $2(8.0)$ & $<0.0001$ \\
\hline Grade 2 & $7(33.3)$ & $12(48.0)$ & \\
\hline Grade 3 & $1(4.8)$ & $11(44.0)$ & \\
\hline
\end{tabular}


Twenty of 36 (55.6\%) cases' tumor subtypes were known in patients with NSCLC. When these patients were analyzed according to the tumor subtypes and grades of esophagitis, no statistically significant difference was observed $(p=0.55)$. The subtypes of these tumors were squamous cell carcinoma in 13 of 20 patients (55.6\%) and adenocarcinoma in 7 patients (35.0\%).

\section{Discussion}

The main goal of thoracic RT is to give the most effective irradiation dose to the tumor while delivering an appropriate dose to normal tissues [3, 4]. The esophagus is exposed to a significant amount of radiation during thoracic irradiation, since it is in a central location [7].

The esophagus should be exposed to an RT dose below tolerated organ rates, and the treatment should be planned using techniques such as IMRT (intensity-modulated radiation therapy) to keep the esophagus out of the irradiation range to avoid acute radiation-induced esophagitis. But unfortunately, this is not often possible because of the position of the esophagus in the mediastinum and, sometimes, the esophagus's proximity to metastatic lymph nodes. For these reasons, the main goal should be to determine an effective preventive agent to protect the esophagus from radiation $[3,6,8]$.

Glutamine is an effective preventive radiation agent [10]. We aimed to estimate the efficiency of oral glutamine in the prevention of radiation-induced acute esophagitis in this retrospective randomized experimental study.

There are several conflicting studies about the prevention of radiation toxicity using glutamine in the literature [7]. After glutamine application, radiation-induced bowel toxicity was delayed and the severity of toxicity was reduced because of the inhibition of bacterial translocation in animal model studies $[7,12]$.

Algara et al. [13] verified the efficiency of glutamine in prevention of radiation-induced acute esophagitis in their study of 75 lung cancer patients. Topkan et al. [7] reported the effective role of glutamine in prevention and/or suspension of incidence and severity of radiation-induced acute esophagitis in a 41-patient retrospective study. Oral glutamine reduced the severity of radiation-induced acute esophagitis in our study in accordance with the literature.

Sause et al. [14] reported no statistically significant difference between patients who only received induction chemotherapy and those who underwent RT only, according to the incidence of acute esophagitis [15]. In our study, there were no statistically significant differences between the patients who received RT with or without concurrent chemotherapy in terms of the grade of acute esophagitis. As the patients were insufficient in number, the therapy regimen and doses could not be analyzed in the chemo-radiotherapy group. There is a great need for extensive studies with large patient populations to detect the effects of chemotherapy drugs on acute esophagitis.

Establishing the approximate length of esophagus radiation exposure to determine the severity and incidence of radiation-induced esophagitis causes contradictory results [15]. Otherwise, Rosenman et al. [16] reported the relationship between the severity of esophagitis and esophagi longer than $13 \mathrm{~cm}$ in length that were exposed to 40-60 Gy radiation.

Some alternative studies reported that the volume of irradiated esophagi was likely associated with radiation-induced acute esophagitis [7, 17]. The relation between esophagitis and varied doses of RT was analyzed in studies that used 3-D RT devices. Topkan et al. [7] identified V55 (the volume of esophagus that was exposed to 55 Gy irradiation) as an important parameter in radiation-induced esophagitis in patients with no glutamine support. Bradley et al. found V60 to be a significant parameter; however, in a study of 75 patients, [17] Algara et al. identified the significance of V50 [13]. When $30 \%$ or less of esophagus volume was exposed to $50 \mathrm{~Gy}$ of radiation, grade II esophagitis was seen in $22 \%$ of patients, but when the volume of esophagus exposed to radiation became larger (more than $30 \%$ ), the grade II esophagitis rate increased to $71 \%$ [14]. We used a two-dimensional RT device, so only the length of the esophagus exposed to radiation was analyzed. The lengths of esophagi ranged between 14 and $21 \mathrm{~cm}$. The length of esophagus exposed to the radiation was not associated with the grade of radiation-induced esophagitis, so there were no statistically significant differences between them.

Metabolized enteral glutamine has similar advanced intestinal protection as the parenteral form [18]. Either an enteral or parenteral form of glutamine should be given to patients for nutritional support $[4,19]$. During metabolic stress, and active tumor growth, $20 \mathrm{~g}$ to $40 \mathrm{~g}$ of glutamine should be applied. Due to costs, glutamine powder forms should be preferred to pills and capsules. The powder form is easy to use and is more absorbable and tolerable. Higher doses of glutamine in this form can be applied to protect intestinal epithelium. Oral glutamine is given three times a day to increase cell connections [4, 18]. Oral glutamine intake before, during, and after RT is recommended in some studies to prevent, delay, and repair radiation-induced esophagitis [7, 9, 17]. In our study, a powder form of oral glutamine was applied (30 g per day) by dividing three equal doses during thoracic RT and for three weeks after treatment, like all of these studies. Oral glutamine application before RT was not possible since our study was retrospective. There is a great need for prospective studies with more patients to obtain more accurate results.

Kozelsky et al. [20] gave oral glutamine to patients and reported that there were no statistically significant differences between the patient group and the control group, who did not receive glutamine, according to incidence and grade of radiation-induced diarrhea, in a 129-patient randomized trial.

Some clinical studies indicate that oral glutamine and L-alanyl-L-glutamine prevent mucositis [20]. Cerchietti et al. [21] determined that intravenous L-alanyl-L-glutamine prevented chemotherapy-induced mucositis in head and neck cancer patients. Also, some other studies reported similar results. However, several studies claim that oral glutamine's protective effect on chemotherapy-induced oral mucositis is insufficient [22, 23]. Savarese et al. [4] reviewed human and animal trials over a 23-year period and reported that oral glutamine decreased the grade 
and incidence of chemotherapy-induced mucositis, irinotecan-induced diarrhea, neuropathy caused by paclitaxel, hepatic veno-occlusive diseases after high-dose chemotherapy or root cell transplantation, and anthracycline cardiotoxicity.

In a 70-patient randomized study, Daniele et al. [24] reported that $18 \mathrm{~g}$ of oral glutamine per day decreased the incidence and severity of diarrhea caused by 5 -fluorouracil.

In conclusion, in this retrospective study, we aimed to determine the protective effect of oral glutamine on radiation-induced acute esophagitis in patients with lung cancer. We established the reduction of the incidence and severity of acute radiation-induced esophagitis during thoracic irradiation resulting from oral glutamine with the data from our study.

The results show that oral glutamine may be an effective protector of esophagus from radiation-induced injury in patients receiving thoracic RT. However, based on comparisons of similar studies, clearly, prospective studies with larger populations of patients are needed.

The authors declare no conflict of interests.

\section{References}

1. Chang JY, Bradley JD, Govindan R, Komaki R. Lung. In: Perez CA, Brady LW (ed.). Principles and Practice of Radiation Oncology. $5^{\text {th }}$ ed. Lippincott Williams \& Wilkins, Philadelphia 2008; 48: 1076109.

2. Carney DN. Lung cancer: time to move on from chemotherapy. N Engl J Med 2002; 346: 126-7.

3. Haasbeek CJ, Slotman BJ, Senan S. Radiotherapy for lung cancer: clinical impact of recent technical advances. Lung Cancer 2009; 64: 1-8.

4. Savarese DM, Savy G, Vahdat L, Wischmeyer PE, Corey B. Prevention of chemotherapy and radiation toxicity with glutamine. Cancer Treat Rev 2003; 29: 501-13.

5. Pignon JP, Arriagada R, Ihde DC, et al. A meta-analysis of thoracic radiotherapy for small-cell lung cancer. N Engl J Med 1992; 327: 1618-24.

6. Beyzadeoğlu M, Ebruli C. Temel Radyasyon Onkolojisi. GATA, Ankara 2008; 109

7. Topkan E, Yavuz MN, Onal C, Yavuz AA. Prevention of acute radiation-induced esophagitis with glutamine in non-small cell lung cancer patients treated with radiotherapy: evaluation of clinical and dosimetric parameters. Lung Cancer 2009; 63: 393-9.

8. Sur RK, Kochhar R, Singh DP. Oral sucralfate in acute radiation esophagitis. Acta Oncol 1994; 33: 61-3.

9. Aksu G, Bakkal H, Fayda M, Sarper BC. Radiation esophagitis, treatment strategies and prevention. Cancer Therapy 2005; 3: 341-6.

10. Bartlett DL, Charland S, Torosian MH. Effects of glutamin on tumor and host growth. Ann Surg Oncol 1995; 2: 71-6.

11. Klimberg VS, Souba WW, Dolson DJ, et al. Prophylactic glutamine protects the intestinal mucosa from radiation injury. Cancer 1990; 66: 71-6.

12. Klimberg V. How glutamine protects the gut during irradiaton. J Crit Care Nutr 1996; 3: 21-5.

13. Algara M, Rodríguez N, Viñals $P$, et al. Prevention of radiochemotherapy-induced esophagitis with glutamine: results of a pilot study. Int J Radiat Oncol Biol Phys 2007; 69: 342-9.

14. Sause W, Kolesar P, Taylor S IV, et al. Final results of phase III trial in regionally advanced unresectable non-small cell lung cancer: Radiation Therapy Oncology Group, Eastern Cooperative Oncology Group, and Southwest Oncology Group. Chest 2000; 117: 358-64.

15. Werner-Wasik M, Pequignot E, Leeper D, Hauck W, Curran W. Predictors of severe esophagitis include use of concurrent chemo- therapy, but not the length of irradiated esophagus: a multivariate analysis of patients with lung cancer treated with nonoperative therapy. Int J Radiat Oncol Biol Phys 2000; 48: 689-96.

16. Rosenman JG, Halle JS, Socinski MA, Deschesne K, Moore DT, Johnson $\mathrm{H}$, Fraser R, Morris DE. High-dose conformal radiotherapy for treatment of stage IIIA/IIIB non-small-cell lung cancer: technical issues and results of a phase I/II trial. Int J Radiat Oncol Biol Phys 2002; 54: 348-56.

17. Bradley J, Deasy JO, Bentzen S, El-Naqa I. Dosimetric correlates for acute esophagitis in patients treated with radiotherapy for lung carcinoma. Int J Radiat Oncol Biol Phys 2005; 58: 1106-13.

18. Anderson PM, Schroeder G, Skubitz KM. Oral glutamine reduces the duration and severity of stomatitis after cytotoxic cancer chemotherapy. Cancer 1998; 83: 1433-9.

19. Robert PR, Zaloga GP. Enteral Nutrition. In: Textbook of Critical Care. Shoemaker WC, $4^{\text {th }}$ ed. W.B. Saunders Company, Philadelphia 2000; 875-97.

20. Kozelsky TF, Meyers GE, Sloan JA, et al. Phase III double blind study of glutamine versus placebo for the prevention of acute diarrhea in patients receiving pelvic radiation therapy. J Clin Oncol 2003; 21: 1669-74.

21. Cerchietti LC, Navigante AH, Lutteral MA, et al. Double-blind, placebo-controlled trial on intravenous L-alanyl-L-glutamin in the incidence of oral mucositis following chemoradiotherapy in patients with head and neck cancer. Int I Radiat Oncol Biol Phys 2006; 65: 1330-7.

22. van Zaanen HC, van der Lelie H, Timmer JG, Fürst P, Sauerwein HP. Parenteral glutamine dipeptide supplementation does not ameliorate chemotherapy induced toxicity. Cancer 1994; 74: 2879-84.

23. Okuno SH, Woodhouse CO, Loprinzi CL, et al. Phase III controlled evaluation of glutamine for decreasing stomatitis in patients receiving fluorouracil (5-FU)-based chemotherapy. Am J Clin Oncol 1999; 22: 258-61.

24. Daniele B, Perrone F, Gallo C, et al. Oral glutamine in the prevention of fluorouracil induced intestinal toxicity: a double blind, placebo controlled, randomised trial. Gut 2001; 48: 28-33.

\section{Address for correspondence}

\section{Seckin Akkucuk MD, PhD}

Department of General Surgery

Medicine School of Mustafa Kemal University

31000 Hatay

Antakya, Turkey

e-mail:sakkucuk@mku.edu.tr

Submitted: 18.12 .2012

Accepted: $\quad 16.10 .2013$ 